\title{
The efficacy of a brief intervention to reduce alcohol misuse in patients with HIV in South Africa: study protocol for a randomized controlled trial
}

\author{
Diana Huis in 't Veld ${ }^{1,2,3^{*}}$, Linda Skaal ${ }^{4,5}$, Karl Peltzer ${ }^{6,7}$, Robert Colebunders $^{1,3}$, John V Ndimande ${ }^{8}$ \\ and Supa Pengpid ${ }^{5}$
}

\begin{abstract}
Background: Alcohol abuse comes with risks for increased morbidity and mortality among patients with HIV. This study aims to determine the prevalence of alcohol use and other risk factors in a sample of primary care patients with HIV in South Africa and to assess a brief intervention to reduce the use of alcohol in this group.

Methods/Design: A single-blinded randomized controlled trial is designed to determine the efficacy of a brief intervention to reduce hazardous alcohol use in patients with HIV. The study will be carried out on out-patients with HIV in two primary healthcare HIV clinics near Pretoria, South Africa. Alcohol use will be assessed with the Alcohol Use Disorder Identification Test questionnaire. Other data that will be collected relate to health-related quality of life, depression, sexual behavior, internalized AIDS stigma, HIV-related information and adherence to antiretroviral therapy (self-reported 7-day recall of missed doses, Visual Analog Scale and pill count). The intervention consists of a brief counseling session to reduce alcohol risk; the control group receives a health education leaflet.
\end{abstract}

Discussion: The findings will be important in the public health setting. If the intervention proves to be efficient, it could potentially be incorporated into the HIV care policy of the Ministry of Health.

Trial registration: Pan African Clinical trial Registry: PACTR201202000355384

Keywords: Alcohol, HIV, South Africa, Intervention

\section{Background}

The use of alcohol in South Africa is among the highest in Africa [1] with a total adult per-capita consumption of 9.51 pure alcohol per year, and a consumption of $34.91 \mathrm{l}$ pure alcohol per year (men $39.64 \mathrm{l}$, women $23.84 \mathrm{l}$ ) among people that drink alcohol [2]. Since South Africa also has one of the highest prevalences of HIV in the world (prevalence estimated to be $17.8 \%$ among adults aged 15 to 49 in 2009) [3], it is possible that a considerable number of persons living with HIV engage in hazardous

\footnotetext{
* Correspondence: dhuisintveld@itg.be

'Department of Epidemiology and Social Medicine, University of Antwerp, Universiteitsplein 1, Antwerp (Wilrijk) 2610, Belgium

${ }^{2}$ FWO Research Foundation Flanders, Egmontstraat 5, Brussels 1000, Belgium Full list of author information is available at the end of the article
}

or harmful alcohol use. Hazardous drinking is defined as a quantity or pattern of alcohol consumption that places patients at risk for adverse health events, while harmful drinking is defined as alcohol consumption that results in adverse events (for example, physical or psychological harm) [4]. Prevalence data on (hazardous) alcohol use in patients with HIV in Africa vary since different measuring tools were used in different study populations. A systematic review by Nakimuli-Mpungu and colleagues on alcohol use, depression and adherence to antiretroviral therapy (ART) in patients with HIV showed a prevalence of alcohol use between 2.5 and 51\%. The prevalence of alcohol use disorders ranged from 2.5 to $31 \%$ [5]. Myer and colleagues reported a prevalence of 
alcohol dependence/abuse of $7 \%$ in patients with HIV in Cape Town [6].

Studies in several African countries have shown a causal link between alcohol use and HIV, and have shown that alcohol use has effects on the course of HIV, including adherence to ART. The prevalence of HIV is considerable higher in adults who have a history of alcohol consumption or frequently use alcohol than in adults who do not use alcohol [7-10]. A systematic review and meta-analysis by Fisher and colleagues confirmed the strong association between alcohol use and HIV infection [11].

The negative effects of alcohol use on the individuals are numerous. High alcohol use is associated with highrisk sexual behavior and risk of HIV [12,13]. Once individuals are infected with HIV, alcohol use is related to low participation in prevention mother-to-child transmission (PMTCT), pre-test and post-test counseling (including returning for test results) $[14,15]$. Overall, there is a late presentation to HIV care in patients that use alcohol, compared with those that do not use alcohol (odds ratio $=3.55,95 \%$ confidence interval $=1.63$ to 7.71) [16]. Adherence to ART is poor if alcohol is used [17-21].

HIV disease progression is accelerated by alcohol use, which is shown by a more likely decline of CD4 T cells to $\leq 200$ cells $/ \mu \mathrm{l}$ and a more frequent detectable viral load in frequent alcohol users, independent of baseline CD4 cell count and HIV viral load, ART use over time, the time since HIV diagnosis, and age and gender [22-24]. Alcohol use can cause liver problems, which could add to the risk of toxicity in patients using ART.

Screening and brief intervention for alcohol reduction in primary care patients has proven effective in reducing alcohol consumption at 6 and 12 months [25]. Results from studies on screening and brief intervention in HIV patients using alcohol, mainly performed in the USA, are not conclusive. One study performed in New York showed improvement in self-report and biological markers (CD4 cell count and HIV viral load) after an eightsession behavioral intervention after 3 months. However, this result was not sustained at 6 months [26]. A multicomponent (including behavioral) intervention showed no significant differences in adherence, CD4 count, viral load or alcohol consumption [27].

Very few reports from resource-limited settings have been published on interventions to reduce alcohol use in HIV-positive patients. One study describes an intervention based on a culturally adapted, six-session (over a 3-month period) cognitive-behavioral therapy to reduce alcohol use among HIV-infected outpatients in western Kenya, whereby the percentages of days abstinent from alcohol before session 1 were 52 to $100 \%$ for women and 21 to $36 \%$ for men. By session 6 this was 96 to $100 \%$ for women and 89 to $100 \%$ for men. The percentages of days abstinent from alcohol effect sizes (Cohen's $d$ ) between the first and last cognitive-behavioral therapy sessions were 2.32 for women and 2.64 for men [28].

This study will measure the prevalence of alcohol use in patients with HIV and assess the efficacy of a brief intervention to reduce alcohol use among selected patients.

\section{Methods/Design}

\section{Design}

The first part of the study will be a screening phase to estimate the prevalence of (hazardous and harmful) alcohol use in the study population. The study design for the efficacy study is a single-blinded randomized controlled trial where information will be collected from patients at inclusion (before the intervention, which is performed in the same session: pre-intervention) and at follow-up of 3 and 12 months.

\section{Setting, study population and participants}

The sample will include out-patients with HIV at the primary care clinics in townships in Gauteng, South Africa. Out-patients with HIV will be screened for hazardous and harmful alcohol use. Patients identified as hazardous drinkers (on the Alcohol Disorder Identification Test (AUDIT) questionnaire) will be randomized into an intervention group or a control group.

\section{Aim of the study}

The aim of the study is to assess the prevalence and severity (hazardous and harmful) of alcohol use in patients with HIV and its associated factors, and to study the efficacy of a brief intervention for hazardous alcohol use in out-patients with HIV in primary health care clinics in townships in South Africa.

\section{Objectives}

The objectives of the screening phase are: to measure the prevalence of alcohol consumption among outpatients with HIV; and to describe drinking patterns, health status, quality of life, sexual behavior and adherence levels among out-patients with HIV, and identify hazardous drinkers needing intervention.

The objectives of the intervention phase are: to compare the level of alcohol consumption, health status, quality of life, level of adherence to ART and sexual behavior among hazardous drinkers between pre-intervention and 3 and 12 months after the intervention; and to compare levels of and changes in alcohol consumption, adherence level to ART, quality of life, health status and number of patients with virological and immunological failure, between intervention and control groups at 3 and 12 months. 


\section{Hypothesis}

Hazardous drinkers with HIV in the intervention group will reduce alcohol drinking more than those in the control group. In patients that reduce alcohol use, a positive effect will be seen in adherence levels to ART, quality of life, health status and virological and immunological response.

\section{Inclusion criteria}

Patients who are 18 years and older, with HIV-1 infection and who are visiting selected outpatient clinics for their HIV care will be eligible for this study. Patients with hazardous alcohol use will be selected using the AUDIT questionnaire (hazardous drinkers score 8 to 19 for men and 7 to 19 for women).

\section{Exclusion criteria}

Patients with mental impairment, patients already undergoing alcohol reduction treatment and pregnant women will be excluded from this study.

\section{Sample size calculation}

The sample size was calculated using Open Epi [29]. Based on the current AUDIT score of 12 among HIV patients, it is assumed that the intervention will reduce the current AUDIT score by $12 \%$ to 10.6 [30,31]. Based on this assumption, the estimated sample size will allow us with $80 \%$ power ( $5 \%$ level of significance) to detect the difference of $12 \%$ between the two groups. This will give a minimum of 99 patients per arm. It is expected that $20 \%$ of participants may be lost prior to completing the 3-month and 12-month follow-up assessments so that the final sample would be 120 per arm. A total of $240 \mathrm{HIV}$ patients (with AUDIT scores 8 to 19 for men or 7 to 19 for women) will be recruited for the study.

\section{Randomization}

Patients fulfilling criteria for selection for this study will be randomized to receive an intervention or to be in the control group. Randomization will be done by concealed, centrally allocated, computer-generated random numbers.

\section{Procedure}

All consecutive HIV-positive patients visiting two outpatient clinics will be asked to provide informed consent to receive a baseline assessment (using the data collection instruments) and screening for alcohol problems. If eligible - meaning an AUDIT questionnaire score of 8 to 19 for men or 7 to 19 for women - a second informed consent will be asked before randomization into the intervention or control group. Patients with a score of 20 and above on the AUDIT (with probable alcohol dependence) will be referred for further management (according to local standard procedures). The research assistant nurse will randomize patients by checking the random numbers that allocate the case to the intervention arm or control arms. The intervention or control procedures will be carried out in all patients, after which they will be followed up at 3 and 12 months (which are standard visit intervals for the follow-up of the HIV care). The research assistant performing the follow-up assessments will be blinded to the intervention allocation of the participant. In the event of a drop-out, at least six individual attempts will be made to contact patients by telephone and letter. Even if a contact was not successful at either follow-up point, further attempts will be made at any next follow-up point. Sampling will occur throughout all hours of clinic operation over a 3-month period. Patients will be offered a drink (soda, juice) during the interviews.

\section{Data collection instruments}

Eight instruments (questionnaires) will be used to collect data. All questionnaires will be administered in English or Tswana, the two languages predominantly spoken by nearly all clinic patients. The questionnaires will be administered at baseline and every follow up visit.

\section{Sociodemographic characteristics}

A researcher-designed questionnaire will be used to record information on participants' age, gender, population group, language, educational level, marital status, highest educational qualification, source of income and residential status.

\section{Health-related quality of life}

The WHOQoL-HIVBREF is based on the WHOQOLHIV measure, one of the two World Health Organization (WHO) quality-of-life instruments for the use in HIVinfected populations [32,33]. The WHOQoL-HIVBREF evaluates the quality of life in six domains and 31 questions.

\section{Depression}

Symptoms of depression will be assessed using the 10item version of the Centers for Epidemiologic Studies Depression Scale [34]. The Centers for Epidemiologic Studies Depression Scale has been widely used in studies on the relationship between HIV and depression [35]. The sensitivity and specificity of the Centers for Epidemiologic Studies Depression Scale 20-item survey has been reported to average $80 \%$ and $70 \%$, respectively, compared with formal diagnostic interview [36]. We will also identify patients who experience more severe depressive symptoms by distinguishing those scoring $\geq 15$ 
out of 30 on the Centers for Epidemiologic Studies Depression Scale 10-item survey [34].

\section{Sexual behavior}

To study the sexual behavior of HIV patients, and specifically those who consume hazardous amounts of alcohol before and after intervention, we included questions on sexual behavior.

\section{Internalized AIDS stigma}

We will use the seven-item internalized AIDS-related stigma scale for people infected with HIV. Items reflect self-defacing beliefs and negative perceptions of people living with HIV/AIDS. In previous studies including South Africa, with the same scale, a Cronbach alpha reliability coefficient of 0.72 to 0.76 was found [37].

\section{Alcohol consumption}

The 10-item AUDIT assesses alcohol consumption level (three items), symptoms of alcohol dependence (three items), and problems associated with alcohol use (four items) [38]. Responses to items on the AUDIT are rated on a four-point Likert scale from 0 to 4 , with a maximum score of 40 points. AUDIT scores higher than 19 indicate more severe levels of risk; scores of 8 to 19 in men and 7 to 19 in women indicate a tendency to problematic drinking. The AUDIT shows excellent sensitivity and specificity in detecting Mini-International Neuropsychiatric Interview-defined dependence/abuse (area under the receiver-operating characteristic curve $=0.96$ ) in HIV patients in South Africa [5].

To reduce the stigma of alcohol use, the WHO suggests integrating the screening of alcohol use with screening for other health-related behaviors [38]. For this reason, two questions will be asked on the use of tobacco products and anthropometric measurements will be taken to assess the risk factor of overweight (height, weight and waist circumference).

\section{HIV-related information}

A researcher-designed patient information extraction sheet will be used to record information related to the HIV infection and will include questions about date of first positive HIV test, start date for ART, ART regimen, co-infections and co-medication. The patient file will be used to obtain additional information. The computerized laboratory data system will be used to obtain the laboratory results. At follow-up, CD4 cell counts and viral load will be obtained from the computerized laboratory data system.

\section{Assessment of adherence to antiretroviral therapy}

For assessing adherence to ART we will use three tools.
Self-reported adherence by recall of missed doses during last 7 days This tool is easy to use and is significantly associated with virological and immunological outcomes [39].

Visual Analog Scale The 30-day Visual Analog Scale provides an overall adherence assessment for a 1-month period. The Visual Analog Scale has been validated in resource-limited settings [40,41]. Adherence levels assessed from the Visual Analog Scale are defined as follows: full adherence, 100\%; partial adherence, between $\geq 95 \%$ and $<100 \%$; and non-adherence, $<95 \%$ of prescribed doses taken in the past 30 days. The Visual Ana$\log$ Scale will be assessed at baseline for patients who are already on ART and at any follow-up visit if the patient is on ART.

Pill count A pill count compares the number of pills that were dispensed and that are remaining at the pill count. A percentage of adherence to ART will be calculated.

\section{Interventions \\ Control group}

Patients in the control group will only receive a health education leaflet on responsible drinking. They will receive the brief intervention only after 12-month followup, if the intervention has proven to be successful.

\section{Intervention group}

Patients in the intervention group will first receive personalized feedback on the AUDIT results. A health education leaflet on responsible drinking will then be given and discussed. Subsequently, simple advice and brief counseling on reducing excessive drinking will be offered during a one-session, 20-minute intervention. Since there is a serious lack of resources in South Africa in HIV care, an efficient intervention has to be short and simple to incorporate into daily practice. Intervention methods whereby patients have to come back for more sessions might in daily practice be unsuccessful because of the time-consuming aspect for those who perform the intervention and because of an expected high patient drop-out rate. A short, one-session intervention has therefore been chosen to be tested in this trial. The brief intervention is based on the WHO brief intervention package for hazardous and harmful drinking [42], which is based on the Information-Motivation-Behavioural Skills Model. The steps of brief counseling are: identify any alcohol-related problems mentioned in the interview; introduce the sensible drinking leaflet, and emphasize the idea of sensible limits, and make sure that patients realize that they are in the medium-risk drinking category; work through the first three sections of the problem-solving manual while mentioning the value of 
reviewing the other sections; describe drinking diary cards; identify a helper; and mention the 3-month and 12-month follow-up.

\section{Counselor training and intervention quality assurance}

The intervention research assistants will be trained to deliver the interventions to the patients. The training consists of role play, general skills training techniques and training on HIV and sexual-related issues. A comprehensive manual for the brief intervention is available and will be used to guide the counseling session. The sites will be visited twice a week by one of the investigators to observe whether there is adherence to the protocol and to offer support and supervision to the research assistants. During regular research meetings, occurring problems will be discussed and solved.

\section{Data analysis}

Virological failure will be defined according to the definition in the South African national guidelines on HIV: a repeat HIV viral load $\geq 1,000$ copies/ml after intense adherence assessment [43]. Immunological failure will be defined according to the WHO definition: a fall of CD4 cell count to pre-therapy baseline (or below), or a 50\% fall from the on-treatment peak value (if known), or a persistent CD4 cell count level below 100 cells $/ \mathrm{mm}^{3}$ [44].

Means, standard deviations, and percentages will be used for descriptive statistics. To examine differences between groups, the $t$ test for continuous data and the chi-square test for categorical data will be used. Generalized linear model repeated measures $2 \times 3$ analysis of variance will be used for comparing observations (alcohol use score) across the three contact periods to demonstrate a treatment intervention $\times$ time interaction. To avoid possible bias from excluding patients with missing values, patterns of missing values will be analyzed. Multiple imputation methods using generalized estimating equating methods, based on all data available in the model, using five imputed datasets, will be used to impute missing data at all contact points (baseline and follow-up at 3 and 12 months). SPSS for Windows version 18.0 (SPSS, Inc., Chicago, IL, USA) will be used for calculations.

\section{Outcomes}

The findings will be important in the public health setting. The AUDIT screening tool has been developed by the $\mathrm{WHO}$ and proved to be applicable in a wide range of settings and target groups, including HIV patients in South Africa. The brief intervention we propose was also developed by the WHO and was proven to be successful in different settings [42]. This makes the intervention widely applicable in different settings and regions. However, the intervention was never tested among patients with HIV infection in South Africa, which this trial aims to do. If the intervention proves to be efficient, it could potentially be incorporated in the South African HIV care guidelines. The generalizability of the trial result may not be extended to other countries, however, where there might be different patterns of alcohol consumption and different cultural beliefs regarding alcohol use and medical care.

\section{Trial status}

Patients are currently being recruited for the trial.

\section{Ethical and governance approval}

Ethical approval was given by the Medunsa Research and Ethics Committee (Project number: MREC/H/165/ 2011: IR). The Tshwane Research Committee has provided approval for the study (Project number: 2011/46).

\section{Abbreviations}

AIDS: acquired immune deficiency syndrome; ART: antiretroviral therapy; AUDIT: Alcohol Use Disorder Identification Test; HIV: human immunodeficiency syndrome; WHO: World Health Organization.

\section{Competing interests}

The authors declare that they have no competing interests.

\section{Authors' contributions}

All authors contributed to the design of the study. DHitV, KP and SP contributed to the training of the research assistants. DHitV and LS contributed to the quality control and supervision of research assistants. DHitV contributed to the data collection, statistical analysis and drafting of the manuscript. All authors read, commented on and approved the final manuscript.

\section{Acknowledgements}

Funding for this study was received from ABMRF, the Foundation for Alcohol Research and the Directorate General for Development Cooperation through the Flemish Interuniversity Council (VLIR-UOS).

\section{Author details}

${ }^{1}$ Department of Epidemiology and Social Medicine, University of Antwerp, Universiteitsplein 1, Antwerp (Wilrijk) 2610, Belgium. ${ }^{2}$ FWO Research Foundation Flanders, Egmontstraat 5, Brussels 1000, Belgium. ${ }^{3}$ Department of Clinical Sciences, Institute of Tropical Medicine, Nationalestraat 155, Antwerp 2000, Belgium. ${ }^{4}$ Department of Social and Behavioral Health Sciences, University of Limpopo, PO Box 215, Medunsa 0204Pretoria, South Africa. ${ }^{5}$ Department of Health System Management and Policy, University of Limpopo, PO Box 215, Medunsa 0204Pretoria, South Africa. ${ }^{6}$ HIV/AIDS, STIs \& TB (HAST) Research Programme, Human Sciences Research Council, 134 Pretorius Street, Pretoria 0002, South Africa. ${ }^{7}$ Department of Psychology, University of Limpopo, Turfloop Campus, Sovenga 0727, South Africa. ${ }^{8}$ Department of Family Medicine and Primary Health Care, University of Limpopo, P.O. Box 222, Medunsa 0204Pretoria, South Africa.

Received: 13 March 2012 Accepted: 21 September 2012 Published: 9 October 2012

\section{References}

1. Global Status Report on Alcohol and Health 2011. http://www.who.int/ substance_abuse/publications/global_alcohol_report/msbgsruprofiles.pdf

2. Substance Abuse. Country Profiles: South Africa. http://www.who.int/ substance_abuse/publications/global_alcohol_report/profiles/zaf.pdf

3. HIV and AIDS estimates (2009) South Africa. http://www.unaids.org/en/ regionscountries/countries/southafrica/

4. Reid MC, Fiellin DA, O'Connor PG: Hazardous and harmful alcohol consumption in primary care. Arch Intern Med 1999, 159:1681. 
5. Nakimuli-Mpungu E, Bass JK, Alexandre P, Mills EJ, Musisi S, Ram M, Katabira E, Nachega JB: Depression, alcohol use and adherence to antiretroviral therapy in sub-Saharan Africa: a systematic review. AIDS Behav 2011, [Epub ahead of print].

6. Myer L, Smit J, Roux LL, Parker S, Stein DJ, Seedat S: Common mental disorders among HIV-infected individuals in South Africa: prevalence, predictors, and validation of brief psychiatric rating scales. AIDS Patient Care STDS 2008, 22:147-158.

7. Bassett MT, MCFarland WC, Ray S, Mbizvo MT, Machekano R, Van de Wijger JHHM, Katzenstein DA: Risk factors for HIV infection at enrollment in an urban male factory cohort in Harare, Zimbabwe. J Acquir Immune Defic Syndr Hum Retrovirol 1996, 13:287-293.

8. Ayisi JG, Van Eijk AM, Ter Kuile FO, Kolczak MS, Otieno JA, Misore AO, Kager PA, Steketee RW, Nahlen BL: Risk factors for HIV infection among asymptomatic pregnant women attending an antenatal clinic in western Kenya. Int J STD AIDS 2000, 11:393-401.

9. Fritz KE, Woelk GB, Bassett MT, MCFarland WC, Routh JA, Tobaiwa O, Stall RD: The association between alcohol use, sexual risk behavior and HIV infection among men attending beerhalls in Harare, Zimbabwe. AIDS Behav 2002, 6:221-228.

10. Hargreaves JR, Morison LA, Chege J, Rutenburg N, Kahindo M, Weiss HA, Hayes R, Buve A, Study Group on Heterogeneity of HIV Epidemics in African Cities: Socioeconomic status and risk of HIV infection in an urban population in Kenya. Trop Med Int Health 2002, 7:793-802.

11. Fisher JC, Bang H, Kapiga SH: The association between HIV infection and alcohol use: a systematic review and meta-analysis of African studies. Sex Transm Dis 2007, 34:856-863.

12. Fisher JC, Cook PA, Kapiga SH: Alcohol use before sex and HIV risk: situational characteristics of protected and unprotected encounters among high-risk African women. Sex Transm Dis 2010, 37:571-578.

13. Woolf-King S, Maisto SA: Alcohol use and high-risk sexual behavior in sub-Saharan Africa: a narrative review. Arch Sex Behav 2011, 40:17-42.

14. Peltzer K, Mlambo G, Phaweni K: Factors determining prenatal HIV testing for prevention of mother to child transmission of HIV in Mpumalanga, South Africa. AIDS Behav 2010, 14:1115-1123.

15. Msuya SE, Mbizvo E, Uriyo J, Stray-Pedersen B, Sam NE, Hussain A: Predictors of failure to return for HIV test results among pregnant women in Moshi Tanzania. J Acquir Immune Defic Syndr 2006, 43:85-90.

16. Abaynew $Y$, Deribew A, Deribe K: Factors associated with late presentation to HIV/AIDS care in South Wollo Zone Ethiopia: a case-control study. AIDS Res Ther 2011, 8:8.

17. Kip E, Ehlers VJ, Van der Wal DM: Patients' adherence to anti-retroviral therapy in Botswana. J Nurs Scholarsh 2009, 41:149-157.

18. Venkatesh KK, Srikrishnan AK, Mayer KH, Kumarasamy N, Raminani S, Thamburaj E, Prasad L, Triche EW, Solomon S, Safren SA: Predictors of nonadherence to highly active antiretroviral therapy among HIV-infected South Indians in clinical care: implications for developing adherence interventions in resource-limited settings. AIDS Patient Care STDS 2010, 24:795-803.

19. Jaquet A, Ekouevi DK, Bashi J, Aboubakrine M, Messou E, Malga M, Traore HA, Zannou MD, Guehi C, Ba-Gomis FO, Minga A, Allou G, Eholie SP, Bissagnene E, Sasco AJ, Dabis F: Alcohol use and non-adherence to antiretroviral therapy in HIV-infected patients in West-Africa. Addiction 2010, 105:1416-1421.

20. Van Geertruyden JP, Woelk G, Mukumbi H, Ryder R, Colebunders R: Alcohol and antiretroviral adherence? What about Africa? J AIDS 2010, 54:e10.

21. Etienne M, Hossain M, Redfield R, Stafford K, Amoroso A: Indicators of adherence to antiretroviral therapy treatment among HIV/AIDS patients in 5 African countries. J Int Assoc Physicians AIDS Care 2010, 9:98-103.

22. Baum MK, Rafie C, Lai S, Sales S, Page JB, Campa A: Alcohol use accelerates HIV disease progression. AIDS Res Hum Retroviruses 2010, 26:511-518.

23. Samet JH, Cheng DM, Libman H, Nunes DP, Alperen JK, Saitz R: Alcohol consumption and HIV disease progression. J Acquir Immune Defic Syndr 2007, 46:194-199.

24. Conigliaro J, Gordon AJ, McGinnis KA, Rabeneck L, Justice AC, Veterans Aging Cohort 3-Site Study: How harmful is hazardous alcohol use and abuse in HIV infection: do health care providers know who is at risk? J AIDS 2003, 33:521-525.

25. Bertholet N, Daeppen JB, Wietlisback V, Fleming M, Burnand B: Reduction of alcohol consumption by brief alcohol intervention in primary care: systematic review and meta-analysis. Arch Intern Med 2005, 165:986-995.
26. Parsons JT, Golub SA, Rosof E, Holder C: Motivational interviewing and cognitive-behavioral intervention to improve HIV medication adherence among hazardous drinkers: a randomized controlled trial. J Acquir Immune Defic Syndr 2007, 46:443-450.

27. Samet JH, Horton NJ, Meli S, Dukes K, Tripp T, Sullivan L, Freedberg KA: A randomized controlled trial to enhance antiretroviral therapy adherence in patients with a history of alcohol problems. Antiviral Ther 2005, 10:83-93.

28. Papas RK, Sidle JE, Martino S, Baliddawa JB, Songole R, Omolo OE, Gakinya BN, Mwaniki MM, Adina JO, Nafula T, Owino-Ong'or WD, Bryant KJ, Carroll KM, Goulet JL, Justice AC, Maisto SA: Systematic cultural adaptation of congnitive-behavioral therapy to reduce alcohol use among HIV-infected outpatients in Western Kenya. AIDS Behav 2010, 14:669-678.

29. Open Epi www.openepi.com

30. Kaner E, Bland M, Cassidy P, Coulton S, Deluca P, Drummond C, Gilvarry E, Godfrey C, Heather N, Myles J, Newbury-Birch D, Oyefeso A, Parrott S, Perryman K, Phillips T, Shenker D, Shepherd J: Screening and brief interventions for hazardous and harmful alcohol use in primary care: a cluster randomised controlled trial protocol. BMC Publ Health 2009, 9:287.

31. Kaner EF, Dickinson HO, Beyer FR, Campbell F, Schlesinger C, Heather N, Saunders JB, Burnand B, Pienaar ED: Effectiveness of brief alcohol interventions in primary care populations. Cochrane Database Syst Rev 2007, 2:CD004148.

32. O'Connell K, Saxena S, Skevington SM, WHOQOLHIV Group: WHOQOL-HIV for quality of life assessment among people living with HIV and AIDS: results from a field test. AIDS Care 2004, 16:882-889.

33. WHOQOLHIV Instruments User's Manual: Scoring and Coding for the WHOQOLHIV Instruments. Geneva: WHO; 2002. http://www.who.int/mental_health/ media/en/613.pdf

34. Andresen EM, Malmgren JA, Carter WB, Patrick DL: Screening for depression in well older adults: evaluation of a short form of the CES-D (Center for Epidemiologic Studies Depression Scale). Am J Prev Med 1994, 10:77-84.

35. Kilbourne AM, Justice AC, Rollman BL, MCGinnis KA, Rabeneck L, Weissman S, Smola S, Schultz R, Whittle J, Rodriquez-Barradas M: Clinical importance of HIV and depressive symptoms among veterans with HIV infection. J Gen Intern Med 2002, 17:512-520.

36. Mulrow CD, Williams JW Jr, Gerety MB, Ramirez G, Montiel OM, Gerber C: Case-finding instruments for depression in primary care settings. Ann Intern Med 1995, 122:913-921.

37. Kalichman SC, Simbayi LC, Cloete A, Mthembuc PP, Mkhontac RN, Ginindza T: Measuring AIDS stigmas in people living with HIV/AIDS: the internalized AIDS related Stigma Scale. AIDS Care 2009, 21:87-93.

38. Babor TF, Higgins-Biddle JC, Saunders JB, Monteiro MG: AUDIT. The Alcohol Use Disorders Identification Test. Guidelines for Use in Primary Care. 2nd edition. WHO/MSD/MSB/01.6a. Geneva: World Health Organization, Department of Mental Health and Substance Dependence.

39. Mannheimer S, Thackeray L, Huppler Hullsiek K, Chesney M, Gardner EM, Wu AW Telzak EE, Lawrence J, Baxter J, Friedland G, Terry Beirn Community Program for Clinical Research on AIDS: A randomized comparison of two instruments for measuring self-reported antiretroviral adherence. AIDS Care 2008, 20:161-169.

40. Maneesriwongul WL, Tulathong S, Fennie KP, Williams AB: Adherence to antiretroviral medication among HIV-positive paitents in Thailand. J Acquir Immune Defic Syndr 2006, 43(Suppl. 1):S119-S122.

41. Sarna A, Luchters S, Geibel S, Munyao P, Kaai S, Khadija S, Kishor M, Hawken M, Van Dam J, Temmerman M: Promoting Adherence through a Directly Administered Antiretroviral Therapy (DAART) Strategy in Mombasa, Kenya. Horizons Research Update. Nairobi: Population Council; 2005.

42. Babor TF, Higgins-Biddle JC: Brief Intervention for Hazardous and Harmful Drinking: A Manual for Use in Primary Care Settings. WHO/MSD/MSB/01.66. Geneva: World Health Organization, Department of Mental Health and Substance Dependence; 2001

43. Clinical Guidelines for the Management of HIV \& AIDS in Adults and Adolescents. http://www.doh.gov.za/docs/factsheets/guidelines/adult_art.pdf

44. Antiretroviral Therapy for HIV Infection in Adults and Adolescents. Recommendations for a Public Health Approach. 2010 Revision. http:// whqlibdoc.who.int/publications/2010/9789241599764_eng.pdf

\section{doi:10.1186/1745-6215-13-190}

Cite this article as: Huis in 't Veld et al:: The efficacy of a brief intervention to reduce alcohol misuse in patients with HIV in South Africa: study protocol for a randomized controlled trial. Trials 2012 13:190. 